\title{
NATIVE SUPERCOLONIES OF UNRELATED INDIVIDUALS IN THE INVASIVE ARGENTINE ANT
}

\author{
Jes S. Pedersen, ${ }^{1,2,3}$ Michael J. B. Krieger, ${ }^{1,4}$ Valérie Vogel, ${ }^{1}$ Tatiana Giraud, ${ }^{1,5}$ And Laurent \\ KELLER $^{1}$ \\ ${ }^{1}$ Department of Ecology and Evolution, University of Lausanne, Biophore, CH-1015 Lausanne, Switzerland \\ ${ }^{2}$ Department of Population Biology, Institute of Biology, University of Copenhagen, Universitetsparken 15, \\ DK-2100 Copenhagen, Denmark \\ ${ }^{3}$ E-mail: jspedersen@bi.ku.dk
}

\begin{abstract}
Kinship among group members has long been recognized as a main factor promoting the evolution of sociality and reproductive altruism, yet some ants have an extraordinary social organization, called unicoloniality, whereby individuals mix freely among physically separated nests. This type of social organization is not only a key attribute responsible for the ecological dominance of these ants, but also an evolutionary paradox because relatedness between nestmates is effectively zero. Recently, it has been proposed that, in the Argentine ant, unicoloniality is a derived trait that evolved after its introduction into new habitats. Here we test this basic assumption by conducting a detailed genetic analysis of four native and six introduced populations with five to 15 microsatellite loci and one mitochondrial gene. In contrast to the assumption that native populations consist of family-based colonies with related individuals who are aggressive toward members of other colonies, we found that native populations also form supercolonies, and are effectively unicolonial. Moreover, just as in introduced populations, the relatedness between nestmates is not distinguishable from zero in these native range supercolonies. Genetic differentiation between native supercolonies was very high for both nuclear and mitochondrial markers, indicating extremely limited gene flow between supercolonies. The only important difference between the native and introduced populations was that supercolonies were several orders of magnitude smaller in the native range $(25-500 \mathrm{~m})$. This size difference has important consequences for our understanding of the evolution and stability of unicolonial structures because the relatively small size of supercolonies in the native range implies that competition can occur between supercolonies, which can act as a break on the spread of selfish mutants by eliminating supercolonies harboring them.
\end{abstract}

Key words.-Invasions, Linepithema humile, relatedness, social evolution, social insects, supercolonies, unicoloniality.

Received July 5, 2005. Accepted January 26, 2006.

Since its inadvertent introduction from South America into all other continents with a Mediterranean climate, the Argentine ant Linepithema humile has invaded vast areas where it has become a major pest (Cole et al. 1992; Passera 1994; Bolger et al. 2000; Sanders et al. 2003). The Argentine ant disrupts or eliminates the native arthropod fauna (Passera 1994; Human and Gordon 1996; Bolger et al. 2000), protects phytophagous insects that devastate plants, destroys fruit crops (Visser et al. 1996), and invades human houses (Bourke and Franks 1995). The ecological domination of this species is thought to stem from its unusual social structure, called unicoloniality, whereby individuals mix freely among physically separated nests. By reducing the costs associated with territoriality, unicoloniality allows high worker densities and effective habitat monopolization by the competitive exclusion of other ant species (Holway et al. 1998; Holway and Suarez 2004). Indeed, of the 17 land invertebrates species listed among the world's worst invaders (http://www.issg. org), five are ant species with documented or inferred unicolonial structures.

Although unicoloniality is a key attribute responsible for the ecological dominance of some ants, it is also a complicating factor and a potential problem for kin selection theory because this mode of social organization leads to an extreme-

${ }^{4}$ Present address: Center for Studies in Physics and Biology, Rockefeller University, 1230 York Avenue, New York, New York 10021-6399.

5 Present address: Ecologie, Systématique et Evolution, Bâtiment 360, Université Paris-Sud, F-91405 Orsay cedex, France. ly low relatedness between nestmates (Hamilton 1964; Crozier 1979; Bourke and Franks 1995; Queller and Strassmann 1998; Queller 2000). Indeed, previous genetic studies on introduced $L$. humile populations failed to demonstrate a greater than zero relatedness among nestmate workers (Kaufmann et al. 1992; Krieger and Keller 2000; Tsutsui and Case 2001; Ingram 2002a; Ingram and Gordon 2003) or gave equivocal results (Ingram 2002b).

The interest in the Argentine ant social organization has been further bolstered by studies of native populations in Argentina. Recent studies have reported that these populations consist of many mutually aggressive colonies with a possible greater than zero relatedness between colony members (Suarez et al. 1999; Tsutsui et al. 2000; Tsutsui and Case 2001). These studies have lead to the view that unicoloniality is a peculiar type of social organization that arose after the introduction of $L$. humile into nonnative habitats (Queller 2000; Tsutsui et al. 2000; Giraud et al. 2002; Tsutsui and Suarez 2003). To explain the transition from multicoloniality to unicoloniality, two hypotheses have been proposed. The first is that introduction has been associated with a genetic bottleneck that reduced genetic diversity at a key recognition locus or several loci (Tsutsui et al. 2000). Alternatively, to account for the fact that the introduced European populations have not been severely bottlenecked, it has been suggested that genetic diversity for recognition alleles was reduced in a "genetic cleansing" process due to selection against less common alleles after introduction (Giraud et al. 2002). Importantly, these two hypotheses and all the controversy that 
TABLE 1. Definitions of central terms in the study of unicolonial social insects and their application in the current study. Terms redefined by the current authors are denoted by an asterisk.

\begin{tabular}{|c|c|}
\hline Term & Definition \\
\hline Nest & $\begin{array}{l}\text { The physical structure inhabited by a colony usually consisting of chambers and galleries. } \\
\text { This is the sampling unit in the current study. }\end{array}$ \\
\hline Nestmates & Individuals inhabiting the same nest. \\
\hline Kin structured or family based & $\begin{array}{l}\text { A colony whose members are offspring of a limited number of queens from the breeding } \\
\text { population. The degree of kin structure can be quantified as the average relatedness be- } \\
\text { tween nestmates }(r) \text { or as the effective number of breeding queens in the colony }\left(n_{\mathrm{e}}\right) \text {. }\end{array}$ \\
\hline Multicolonial* & $\begin{array}{l}\text { A multicolonial species is one that can form kin-structured colonies. A multicolonial pop- } \\
\text { ulation consists of several such colonies that are generally mutually aggressive and ge- } \\
\text { netically differentiated. }\end{array}$ \\
\hline Unicolonial* & $\begin{array}{l}\text { A unicolonial species is one that can form supercolonies. A unicolonial population con- } \\
\text { sists of one or several supercolonies. }\end{array}$ \\
\hline Structured population & $\begin{array}{l}\text { A population in which there is spatial variation in allele frequencies due to nonrandom } \\
\text { mating. This can arise because of limited dispersal of sexuals or subdivision of the } \\
\text { population into isolated breeding units (often called subpopulations). In either case } F_{\text {IT }} \\
>0 \text {. }\end{array}$ \\
\hline
\end{tabular}

arose about them (cf. Queller 2000; Starks 2003; Tsutsui and Suarez 2003; Tsutsui et al. 2003) are based on the assumption that native populations are indeed multicolonial and consist of many kin-structured colonies.

However, recent findings on the social organization of introduced populations (Jaquiéry et al. 2005) indicate that the genetic data and analyses performed in native populations (Suarez et al. 1999; Tsutsui et al. 2000) do not permit the unambiguous conclusion that the social organization of native populations is fundamentally different from that of introduced populations. In their studies Tsutsui et al. (2000) and Tsutsui and Case (2001) compared the level of genetic identity (relatedness coefficient, $F_{\mathrm{ST}}$, and proportion of shared alleles) within and between groups of nests that were considered to belong to the same colony on the basis of aggression tests. They found significant differentiation between colonies, but the data do not allow us to determine whether the genetic similarity of members of the same colony stems from the existence of family-based colonies consisting of related individuals or from population structuring at a larger scale. This is an important issue because a recent study in Europe (Jaquiéry et al. 2005) revealed that introduced populations can, in fact, comprise several supercolonies, which are aggressive to each other. The detailed study of a contact zone between two European supercolonies further demonstrated a complete lack of gene flow and a strong genetic differentiation between supercolonies (Jaquiéry et al. 2005).

\section{Defining and Detecting Social Organization}

The findings of several near supercolonies of the Argentine ant beg for a revised definition of the terms unicoloniality and supercolonies, and a reassessment of the evidence that social organization really differs between native and introduced populations. The term unicolonial was coined by Hölldobler and Wilson (1977, p. 11) to describe "'ant species in which no colony boundaries exist and local populations are comprised of networks of intercommunicating aggregations of workers, brood, and fertile queens.... Such species have been referred to as unicolonial, or more precisely as forming unicolonial populations, as opposed to the more frequent multicolonial ant species in which intercolony recognition and aggression are the rule.' Consequently, unicoloniality has generally been used to define species rather than populations (Crozier 1979; Passera 1994; Bourke and Franks 1995; Queller and Strassmann 1998), but the occurrence of aggression between $L$. humile supercolonies in introduced populations demonstrates that the classification of a species as being unicolonial or multicolonial depends on the geographic scale considered. Thus, if a sampled L. humile population contains several supercolonies, both internest aggression and significant genetic differentiation between nests aggressive to each other will be detected. By contrast, if the sampled nests all belong to the same supercolony, no behavioral colony boundaries and no genetic differentiation between nests will be found. To make a clear distinction between the social organization within colonies and the structure of colonies within a population we propose the definitions of supercolonies, unicoloniality, and multicoloniality given in Table 1.

In addition to the defining features given in Table 1, unicolonial species with supercolonies also have two other important properties. The first is that nests typically contain a large number of queens (Hölldobler and Wilson 1977, 1990; Passera 1994; Bourke and Franks 1995). The other is that matings occur randomly within supercolonies with queens frequently mating with males originating from their own nest (Passera 1994). The outcome is that supercolonies are close breeding units with no or minimal internal genetic differentiation between nests. In that respect, their genetic population structure is similar to that of solitary organisms but differs strongly from those of multicolonial species which form family-based colonies resulting in a significant genetic differentiation between colonies. Moreover, nonparasitic multicolonial species usually avoid mating between nestmates by engaging in large mating flights, hence preventing 
inbreeding from mating among relatives (Bourke and Franks 1995; Crozier and Pamilo 1996).

All introduced L. humile populations studied so far appear to be unicolonial (Markin 1970; Krieger and Keller 2000; Tsutsui et al. 2000; Tsutsui and Case 2001; Ingram 2002a,b; Ingram and Gordon 2003). A large-scale study in Europe revealed the existence of two supercolonies, with the main one ranging over $6000 \mathrm{~km}$ of coastline, from Spain to Italy (Giraud et al. 2002). Workers of the same supercolony are never aggressive to each other despite the large geographical distance, whereas workers are invariably aggressive between supercolonies (Giraud et al. 2002). Similar results were obtained in California where several supercolonies have been identified (Suarez et al. 2002; Tsutsui et al. 2003). Studies in the contact zone between the two European supercolonies also revealed that they have completely separate gene pools with none of the 332 genotyped individuals being admixed despite the fact that some nests of the two supercolonies were separated by less than $30 \mathrm{~m}$ (Jaquiéry et al. 2005). Behavioral studies also revealed that a high proportion of matings occur between individuals of the same nest. Queens of the Argentine ant do not participate in a mating flight (Newell and Barber 1913; Passera and Keller 1990), and they generally mate in their parental nest a few days after eclosion from the pupae (Newell and Barber 1913; Keller and Passera 1992; Passera and Keller 1992). Males have been frequently observed in mating flights and/or captured in aerial traps (Newell and Barber 1913; Markin 1970; Benois 1973), and they tend to disperse when there are no virgin females in their parental nest (Passera and Keller 1994). Although queens tend to prefer mating with males from other colonies (Keller and Passera 1993), they readily mate with males of their own colony (Keller and Passera 1992) and fail to discriminate between related and unrelated males (Keller and Fournier 2002). Since colonies typically contain large numbers of queens, and because queens frequently move between nests, intranidal mating is not associated with any significant level of inbreeding (Krieger and Keller 2000; Ingram 2002a).

The available data on native populations do not allow us to determine whether the significant genetic differentiation that has been observed between groups of nests aggressive to each other stems from the presence of family-based colonies or the sampling of several supercolonies. This is an important distinction because, if supercolonies also occur in native populations, this implies that there has not been a major shift in social organization after introduction in new habitats. Rather, it may simply be that the colonization of new habits has allowed the development of larger supercolonies than in the native habitat, and the hypotheses proposed to explain the shift in social organization (Tsutsui et al. 2000; Giraud et al. 2002) may be irrelevant.

\section{The Current Study}

The first aim of this study was to conduct a detailed population genetic study to determine whether the social structure of native populations is really fundamentally different from that of introduced populations. To this end, we studied four native populations from Argentina using a set of five to 15 microsatellite loci for precise estimation of nestmate re- latedness and $F$-statistics. These microsatellite analyses were supplemented by data on mitochondrial DNA (mtDNA) haplotypes and worker aggression tests to obtain independent information on the genetic and behavioral relationships of the nests studied. Our aim was to determine whether native populations consist of family-based colonies or of supercolonies (Table 1). In both cases it is predicted that colonies (or supercolonies) are genetically differentiated so that workers of the same colony (supercolony) have more similar alleles than a random sample of workers from the entire population. This differentiation will translate into positive estimates of nestmate genetic relatedness $(r)$ and $F_{\mathrm{ST}}$ (either pairwise or overall among nests). However, the two hypotheses make different predictions about the causes underlying this differentiation. If native populations consist of family-based colonies, genetic differentiation should stem from colonies containing a limited number of reproductive queens (cf. Ross 2001). Moreover, these queens should, as typically occurs in multicolonial species, have mated with unrelated males from the entire population resulting in colonies not being closed breeding units. Accordingly, the overall inbreeding coefficient $\left(F_{\mathrm{IT}}\right)$ of nests collected in a given locality should be close to zero. Such a lack of detectable inbreeding is characteristic of social insects with a conventional type of multicolonial social organization (Bourke and Franks 1995; Crozier and Pamilo 1996). By contrast, if native populations also form supercolonies, the genetic differentiation between nests of different supercolonies should not result from nests containing a limited number of reproductive queens, but from supercolonies being closed breeding units in which males and queens mate randomly. Accordingly, the genetic differentiation between supercolonies will result in a Wahlund effect and a positive $F_{\text {IT }}$ value when nests are sampled from more than one supercolony. Under such conditions it is necessary to correct for the Wahlund effect when estimating relatedness (for extensive discussions of this problem see Pamilo 1983, 1985; Ross 2001). Correcting for the Wahlund effect allows us to estimate the corrected relatedness coefficient $r^{*}$, which reflects the true effective number of breeding queens per colony, $n_{\mathrm{e}}$ (Ross 2001). If supercolonies are in fact unicolonial and contain numerous reproductive queens, the corrected relatedness between nestmate workers should be effectively zero. In sum, if native populations consist of family-based colonies, this should translate into $F_{\text {IT }}=0$ and $r>0$ so that the effective number of queens $\left(n_{\mathrm{e}}\right)$ is limited (Ross 2001). By contrast, if native populations consist of supercolonies, this should translate into $F_{\text {IT }}>0$ and $r>0$, but corrected $r^{*}=0$ and $n_{\mathrm{e}}$ approaching $\infty$.

In addition to elucidating whether there has been a shift in social organization after introduction in new habitats, population genetic studies of native populations are critical to determine whether kin selection may operate in a system with supercolonies. Theoretical studies have revealed that the relatedness coefficient relevant for the evolution of social interactions should be estimated in the "economic neighborhood," that is, the scale at which intraspecific competition generally takes place (Taylor 1992; Kelly 1994; Queller 1994; Griffin and West 2002). Thus, if supercolonies occur in the native range of the Argentine ant, and if their size is much smaller than that of introduced populations, as sug- 
gested by previous studies based on aggression tests (Suarez et al. 1999; Tsutsui et al. 2000; Heller 2004), then it might be that competition between supercolonies may provide the conditions for kin selection to operate within the system (see Discussion).

The second aim of this study was to compare the kin and population-genetic structure of the native populations studied with those of six introduced populations from the Americas, Europe, Australia, and Hawaii. The use of a large number of markers also allowed us to accurately determine the relatedness between colony members of introduced populations. Previous studies (Kaufmann et al. 1992; Krieger and Keller 2000; Ingram 2002a,b) conducted on some of these populations were performed either with moderately polymorphic markers, few markers, and/or limited sample sizes with the result that they had limited power to significantly detect small differences of relatedness. However, even low degrees of relatedness between colony members may maintain cooperation by kin selection (Rissing and Pollock 1988; Bourke and Franks 1995), begging for a precise estimate of relatedness between colony members in introduced populations.

\section{Materials And Methods \\ Population Samples}

We collected Linepithema humile workers from 158 nests in 10 populations. Information on the habitat type (natural, rural, or urban) and the number of nests per population are given in Table 2 (see also Reuter et al. 2005). Populations were categorized as native or introduced according to Wild (2004) and as invasive when they had displaced native ant species and achieved local dominance after introduction. Two populations were sampled in Argentina outside the species' native range (Wild 2004). Sampling the Argentinean localities was done along transects spanning the entire population ranges with the position of nests recorded by a combination of GPS (Garmin Ltd., Romsey, U.K.) and tape measures. All samples were stored in $97 \%$ ethanol and kept at $-20^{\circ} \mathrm{C}$ until genetic analyses.

\section{Behavioral Assays}

To determine whether native populations were composed of one or several behaviorally distinct colonies, we conducted standard aggression tests (Holway et al. 1998; Giraud et al. 2002) within all Argentinean populations except Aminga (Table 2). In general, five trials were conducted for each pair of nests, and each nest was used only once. Aggression between workers of different nests indicates that nest belong to different colonies (Suarez et al. 1999; Tsutsui et al. 2000). We furthermore tested pairs of workers from different Argentinean populations to confirm that discrimination against members of other colonies was efficient at this level. Because introduced populations are known to be unicolonial and composed of single supercolonies (see above), we did not conduct behavioral tests in these populations, and lack of aggression was assumed.

\section{Genetic Analyses}

DNA was extracted from 96-415 (total 1955) workers per population using a standard phenol-chloroform protocol or

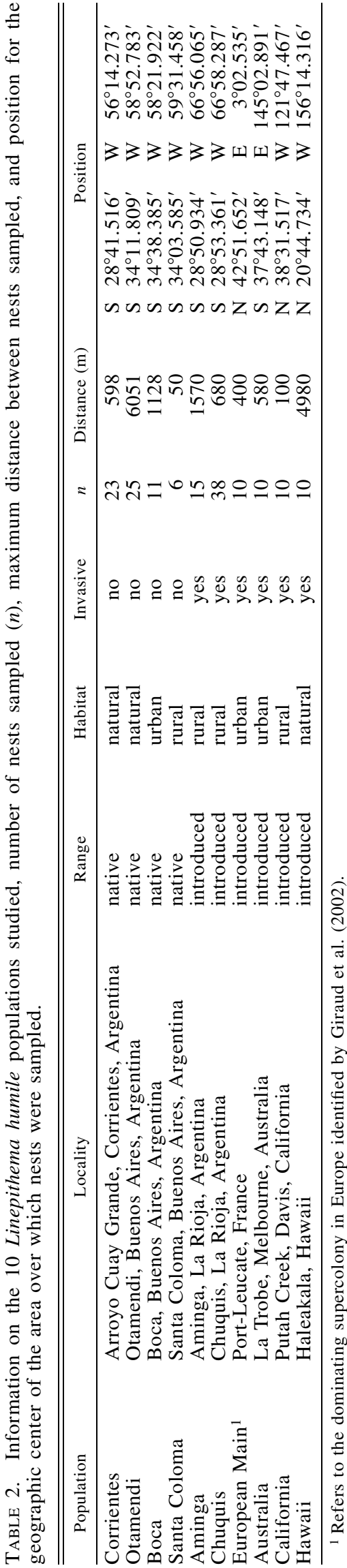


the Puregene DNA Isolation Kit (Gentra Systems, Minneapolis, MN). To study the optimal set of variable genetic markers, we first genotyped 32-100 workers per population at the 22 microsatellite loci that were available at the time when analyses were performed (Krieger and Keller 1999; Tsutsui et al. 2000). We then selected a minimum of five highly polymorphic loci per population. In Corrientes, Otamendi, and Boca, we used Lhum-11, Lhum-13, Lhum-19, Lhum-28, and Lhum-35. In Aminga and Chuquis we used Lhum-3, Lhum-11, Lhum-12, Lhum-35, and Lihu-M1. In five populations suspected to be unicolonial (Santa Coloma, European Main, Australia, California, and Hawaii), we used all loci exhibiting polymorphism within populations (10-15 per population) in order to maximize the power of detecting within-colony relatedness and/or population genetic structure. Unicoloniality of the native population in Santa Coloma was suspected due to its small size (maximum extent $50 \mathrm{~m}$; Table 2).

We also determined the mitochondrial haplotype of one to two workers per nest (total 70) in the four native populations. A 524 bp sequence of the cytochrome $b$ gene was amplified using the primers L-LhCb (5'-GGGCAACAGTTATTACA AACTTAGTG-3') and R-LhCb (5'-TAAGGGTATTCAAT TGGTTGGG-3') which were developed for this study. Polymerase chain reaction (PCR) reactions were done in $50-\mu 1$ volumes with a final concentration of $25 \mathrm{pM}$ of each primer, $0.05 \mathrm{mM}$ of each dNTP, $1.5 \mathrm{mM}$ of $\mathrm{MgCl}_{2}$, and 1 unit of Taq polymerase (Qiagen, Valencia, CA). Amplification involved an initial step at $94^{\circ} \mathrm{C}$ for $3 \mathrm{~min}$, followed by 35 cycles at $92^{\circ} \mathrm{C}$ for $30 \mathrm{sec}, 60^{\circ} \mathrm{C}$ for $30 \mathrm{sec}$, and $72^{\circ} \mathrm{C}$ for $1 \mathrm{~min}$. PCR products were purified using the QIAquick purification kit (Qiagen) and were directly sequenced in both directions on an ABI $377 \mathrm{XL}$ automated sequencer (Applied Biosystems, Foster City, CA) using the BigDye terminator ready-reaction kit. Sequence data were edited and compiled using Sequencher 3.0 (Gene Codes Corp., Ann Arbor, MI) and aligned sequences were compared with MacClade 3.08 (Maddison and Maddison 1992).

\section{Statistical Analyses}

The mean $( \pm \mathrm{SE})$ genetic relatedness $(r)$ and inbreeding coefficient $\left(F_{\text {IT }}\right)$ of nestmate workers were estimated by using the population as a reference and jackknifing over loci. The significance of the relatedness and inbreeding estimates was evaluated with exact tests of population differentiation and of Hardy-Weinberg proportions at the population level, respectively, using 15,000 randomizations in both cases (Goudet et al. 1996). All of the above calculations and tests were performed with FSTAT 2.9.3.2 (http://www2.unil.ch/popgen/ softwares/fstat.htm; Goudet 1995) with CapF applied as the estimator of $F_{\text {IT }}$. We also performed a combined analysis with Relatedness 5.0.8 (http://www.gsoftnet.us/GSoft.html; Queller and Goodnight 1989) for the five populations with presumed unicolonial structure to obtain a more accurate overall estimate of relatedness in this type of population. Because populations differed in which loci were polymorphic, we estimated standard errors of $r$ by jackknifing over nests.

The effective number of queens per colony $\left(n_{\mathrm{e}}\right)$, which expresses the number of unrelated, singly mated, and equally productive queens that would account for a specific observed genetic relatedness of nestmates (Ross 2001), was calculated from the worker relatedness values (Pedersen and Boomsma 1999). The assumptions of single mating and equal share of worker production are supported by previous studies (Keller and Passera 1992; Krieger and Keller 2000; Fournier and Keller 2001). When the Hardy-Weinberg test rejected the assumption of random mating, the direct estimate of worker relatedness $(r)$ was replaced by the estimator $r^{*}$ ("inbreeding corrected relatedness"'; (Pamilo 1985) which corrects for the inflating effect of genetic substructuring of the reference population (see above). Tablewide corrections of probabilities were done by applying the sequential Bonferroni method (Rice 1989).

To determine whether population structuring originated from division into genetically isolated subpopulations or from isolation by distance we used the software BAPS 2.0 (http://www.rni.helsinki.fi/ jic/bapspage.html), which implements a Bayesian approach to cluster groups of individuals (in this case nestmate workers) who are likely to come from the same randomly mating subpopulation (Corander et al. 2003, 2004). Estimations were done with 50,000 iterations with thinning $=3$, following a burn-in period of 10,000 . This software further calculated the average genetic differentiation $F_{\mathrm{ST}} \pm \mathrm{SD}$ under the estimated models for partitioning of the population using 15,000 Gibbs samples. Putative isolation by distance was analyzed by testing the correlation of geographic and genetic $\left(F_{\mathrm{ST}}\right)$ distances between nest samples applying the procedure for Mantel tests in FSTAT 2.9.3.2 using 15,000 permutations.

An analysis of molecular variance (AMOVA; Excoffier et al. 1992) was conducted in Arlequin 2.001 (Schneider et al. 2001) with a sequence distance matrix assuming the Kimura 2P mutation model to analyze the haplotype data.

\section{RESULTS}

\section{Population Characteristics}

The information available from field observations and local inhabitants showed that the six introduced populations were all invasive (F. Cuezzo, J. Briano, R. H. Crozier, P. Krushelnycky, and P. S. Ward, pers. comm.). In all cases, the Argentine ants had replaced the majority of native ants present before the introduction. Moreover, the density of nests and Argentine ant workers was invariably very high. Importantly, this was also true for the introduced populations in Argentina.

Discrimination against alien workers was efficient as assays with individuals from two different Argentinean populations showed aggression in 93\% (range 80-100\%) of the cases ( $n=110$ trials for eight population pairs). Aggression between workers from different nests of the same population was found in three of the four native localities, occurring in $3.4 \%(2 / 59)$ of the assays in Corrientes, $43 \%$ (20/47) of the assays in Otamendi, and 34\% (12/35) of the assays in Boca. In contrast, no aggression was detected in Santa Coloma (five trials). Aggression was also absent in the Argentinean introduced population tested (Chuquis, 80 trials). 
TABLE 3. Population and colony structure in native and introduced populations of Linepithema humile. $n$, number of individuals; $l$, number of variable loci studied; $F_{\mathrm{IT}}$, inbreeding coefficient; $r$, genetic relatedness of nestmate workers; $n_{\mathrm{e}}$, effective number of reproducing queens per colony with $95 \%$ confidence interval (CI); SE, standard errors obtained from jackknifing over loci; $P$, probabilities in randomization tests (see Materials and Methods for explanation) with Bonferroni corrected significance levels: ns, not significant; ** nominal $P<0.01$.

\begin{tabular}{|c|c|c|c|c|c|c|c|c|c|c|}
\hline Population & Range & $\begin{array}{l}\text { Aggres- } \\
\text { sion }\end{array}$ & $n$ & $l$ & $F_{\mathrm{IT}} \pm \mathrm{SE}$ & $P$ & $r \pm \mathrm{SE}$ & $P$ & $n_{\mathrm{e}}$ & $95 \% \mathrm{CI}$ \\
\hline Corrientes & native & + & 240 & 5 & $0.055 \pm 0.015$ & $<7 \times 10^{-5 * *}$ & $0.059 \pm 0.005$ & $<7 \times 10^{-5 * *}$ & $\infty$ & $\infty$ \\
\hline Otamendi & native & + & 369 & 5 & $0.212 \pm 0.021$ & $<7 \times 10^{-5 * *}$ & $0.327 \pm 0.017$ & $<7 \times 10^{-5 * *}$ & $\infty$ & $\infty$ \\
\hline Santa Coloma & native & - & 96 & 15 & $0.026 \pm 0.055$ & $0.081 \mathrm{~ns}$ & $0.000 \pm 0.005$ & $0.699 \mathrm{~ns}$ & $\infty$ & $75-\infty$ \\
\hline Aminga & introduced & - & 224 & 5 & $0.038 \pm 0.019$ & $0.014 \mathrm{~ns}$ & $0.005 \pm 0.010$ & $0.016 \mathrm{~ns}$ & 150 & $38-\infty$ \\
\hline Chuquis & introduced & - & 415 & 5 & $0.022 \pm 0.032$ & $0.052 \mathrm{~ns}$ & $-0.007 \pm 0.006$ & $0.361 \mathrm{~ns}$ & $\infty$ & $375-\infty$ \\
\hline European Main & introduced & - & 100 & 10 & $0.015 \pm 0.019$ & $0.242 \mathrm{~ns}$ & $0.006 \pm 0.013$ & $0.242 \mathrm{~ns}$ & 125 & $21-\infty$ \\
\hline Hawaii & introduced & - & 100 & 10 & $0.003 \pm 0.028$ & $0.444 \mathrm{~ns}$ & $0.005 \pm 0.015$ & $0.011 \mathrm{~ns}$ & 150 & $20-\infty$ \\
\hline
\end{tabular}

\section{Inbreeding and Kin Structure}

Population estimates of inbreeding and relatedness coefficients, their associated test statistics, and derived parameters are given in Table 3. Three of four native populations showed a statistically significant $F_{\text {IT }}$ value, indicating nonrandom mating at the population level. By contrast, the inbreeding coefficient was not significantly different from zero in any of the six introduced populations (after Bonferroni correction).

A similar pattern was uncovered for relatedness values. When not corrected for the effect of inbreeding, the relatedness among nestmates was significantly greater than zero in the three native populations for which $F_{\text {IT }}$ was positive (Corrientes, Otamendi, and Boca), whereas the values were

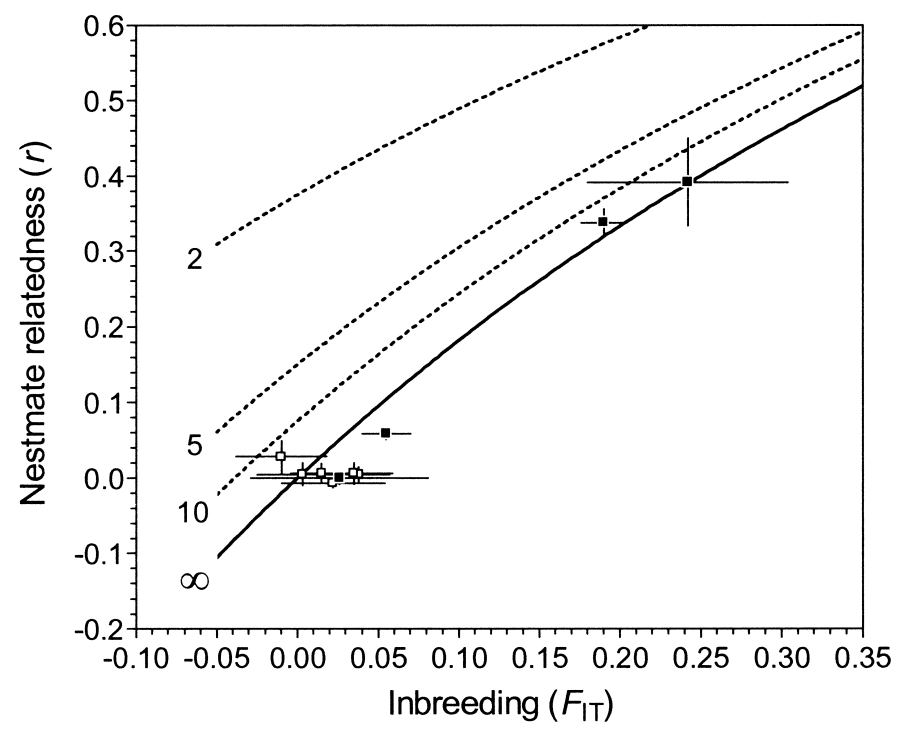

FIG. 1. The association of the inbreeding coefficient $\left(F_{\mathrm{IT}}\right)$ and estimated nestmate genetic relatedness $(r)$ in 10 populations of $\mathrm{Li}$ nepithema humile. Native and introduced populations are indicated by closed and open squares, respectively. The estimates of $F_{\text {IT }}$ and $r$ are given with their standard errors. Isoclines for the effective number of queens per colony $\left(n_{\mathrm{e}}\right)$ are shown, with the full line indicating that all queens in the breeding population have an equal probability of contributing to the worker production in each nest $\left(n_{\mathrm{e}}=\infty\right)$. very close to and not significantly greater than zero in the seven remaining populations (Table 3 ). The overall relatedness in the five populations where workers were genotyped at all 22 loci (Santa Coloma, European Main, Australia, California, and Hawaii) was $r=0.0093 \pm 0.0070$ and not significantly different from zero $(n=46$ nests; one-tailed $t$-test, $P=0.095)$ with $r=0$ and 0.021 as the lower and upper $95 \%$ confidence limits. This corresponds to an effective number of 81 unrelated queens per nest $(95 \%$ confidence interval: $36-\infty)$. A power analysis showed that a true relatedness as low as 0.0067 would have been detected with a probability of $95 \%$ in at least one of the five populations analyzed.

Correcting for the inflating effect of inbreeding had a strong effect on the relatedness values in the three native populations where $F_{\text {IT }}$ was significantly positive, so that the corrected relatednesses in all cases were reduced to zero. Importantly, the relatedness values of all populations were close to zero once corrected for the effect of inbreeding. Accordingly, the estimated effective number of queens $\left(n_{\mathrm{e}}\right)$ was high in all populations with the upper 95\% CL always including $\infty$ (Table 3$)$.

The relationships between the level of inbreeding, nestmate relatedness, and the effective queen number per colony are illustrated in Figure 1. All introduced populations clustered in an area characterized by no inbreeding; nestmate relatedness indistinguishable from zero; and, accordingly, very high estimates of colony queen number. By contrast, native populations showed variability in their level of structuring, as indicated by zero-to-high inbreeding coefficients. However, as for the introduced populations, all four native populations had an equally high effective queen number per colony.

\section{Detailed Structure of Native Populations}

The Bayesian analysis of microsatellite data supports the view that three of the four native populations consist of several supercolonies. The estimated number of distinct genetic subpopulations was two in Corrientes (Bayesian posterior probability, $P>0.99), 19$ in Otamendi $(P>0.99)$, three or four in Boca $(P=0.89$ and 0.11 , respectively), and one in Santa Coloma $(P>0.99)$. The nest colors in Figure 2 depict which subpopulations the nests were assigned to along the 
Corrientes $(C=2, P>0.99)$

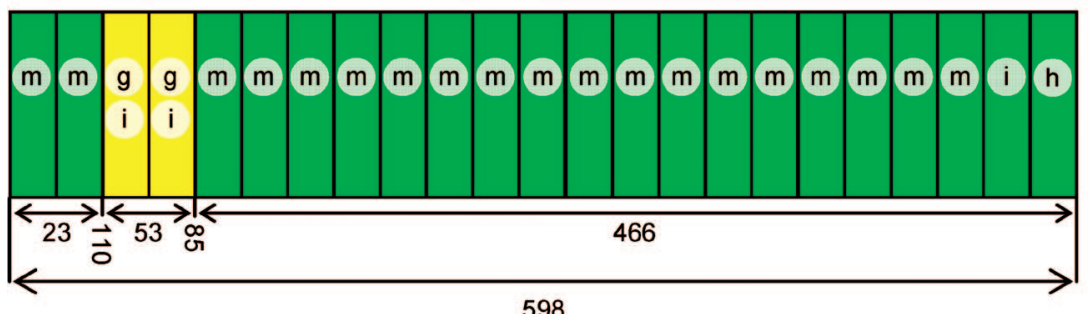

598

Otamendi $(C=19, P>0.99)$

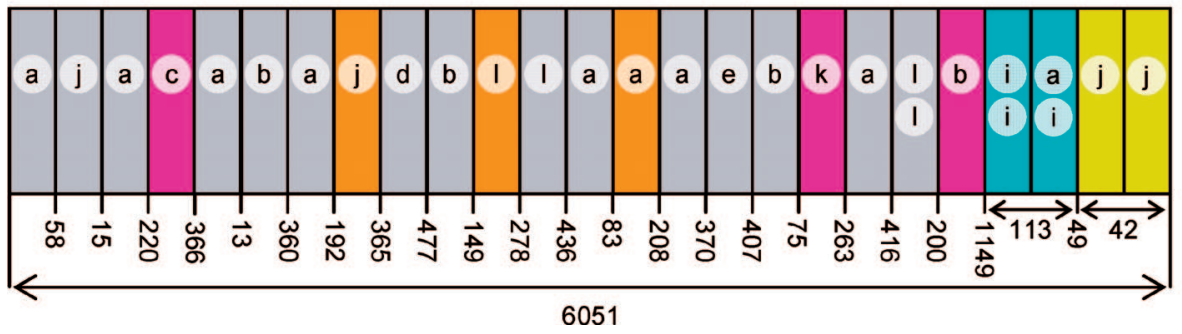

Boca $(C=3, P=0.89 ; C=4, P=0.11)$

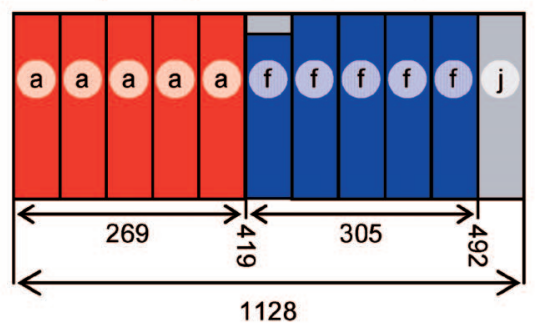

Santa Coloma $(C=1, P>0.99)$

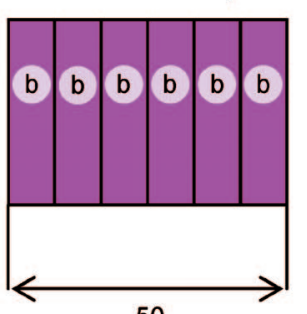

50

FIG. 2. Putative supercolonies within four native populations of Linepithema humile. Nest samples are organized in transects and indicated by rectangles. Each nest is assigned to a supercolony by a probability corresponding to the proportion of the rectangle having the specific color of this supercolony. Gray indicates supercolonies only represented by a single nest in our samples. The resulting number of supercolonies $(C)$ is given with its Bayesian posterior probability $(P)$. The distribution of cytochrome $b$ haplotypes is shown by small letter labels within nest rectangles. The vertical numbers give the distance in meters between the closest nests of different supercolonies and the horizontal numbers the range in meters of the supercolonies and populations sampled.

transect, with gray indicating cases where a subpopulation is represented by only a single nest in the sample. Importantly, the composition of subpopulations was not an artifact stemming from genetic isolation by distance because only an insignificant proportion $(0.6 \%)$ of the genetic variation among subpopulations could be attributed to the geographic distance between them (Pearson $r=0.078$; one-tailed combined Mantel test, $P=0.21)$.

The view that the genetic subpopulations correspond to supercolonies was supported by the results of the aggression tests. Whereas aggression never occurred between pairs of nests $(n=14)$ assigned to the same subpopulation (supercolony), aggression occurred in more than $71 \%$ of the pairs $(n=21)$ of nests assigned to different subpopulations (supercolonies). This difference was highly significant (Fisher's exact test, $P<0.0001$ ), demonstrating a clear association between the behavioral and genetic data.

The genetic differentiation between supercolonies defined on the basis of the genetic assignment tests ranged from $F_{\mathrm{ST}}$ $=0.095 \pm 0.008( \pm \mathrm{SD})$ in Corrientes to $0.248 \pm 0.006 \mathrm{in}$ Otamendi and $0.252 \pm 0.007$ in Boca $\left(P<10^{-5}\right.$ for all). These values agree with the estimates of overall inbreeding reported in Table 3. The distribution of mitochondrial haplotypes also coincided to a large extent with the boundaries of supercolonies as characterized by the microsatellite allele frequencies. Several supercolonies contained only one or a few haplotypes (13\% of total variance; Fig. 2), and the differentiation among supercolonies of the same population was extremely high $\left(\Phi_{\mathrm{ST}}=0.845: 73 \%\right.$ of total variance explained, $P<10^{-5}$; the remaining $14 \%$ of the variance is distributed among populations).

Some supercolonies did not occupy a continuous range along the transect but were intersected by other supercolonies (Fig. 2). An analysis of the three clearest instances of split supercolonies in Corrientes and Otamendi revealed little or no genetic differentiation between the sectors of the same supercolony. There was no genetic differentiation $\left(F_{\mathrm{ST}}=\right.$ $0.000 \pm 0.002 \mathrm{SE}, P=0.19$ ) between the two parts (separated by minimum $53 \mathrm{~m}$ ) of the dominating Green supercolony in Corrientes and, although significant, the differentiation among parts of the two split supercolonies in Otamendi was very small (Magenta supercolony: $F_{\mathrm{ST}}=0.020 \pm 0.006, n$ $=3$; Orange supercolony: $0.048 \pm 0.012, n=3 ; P<0.003$ for both; average distance between parts: $2.1 \mathrm{~km}$ ).

Most supercolonies were only represented in our sample by one or a few nests, preventing an accurate analysis of the kin structure at the colony level. However, data from the main part of the Green supercolony in Corrientes revealed that relatedness between nestmates was close to zero $(r=$ $0.003 \pm 0.005 ; n=19$ nests; $P=0.063)$, corresponding to an effective queen number of 250 (95\% CI: 56- $\infty$ ). Furthermore, a combined analysis of all supercolonies in Corrientes, Otamendi, and Boca with multiple nests sampled per supercolony also revealed an average relatedness not significantly different from zero $(r=0.022 \pm 0.013 ; n=8$ supercolonies; $P=0.069$ ). Moreover, the slightly positive relatedness value was due to a modest, but significantly positive, inbreeding coefficient $\left(F_{\mathrm{IT}}=0.070 \pm 0.024 ; P=0.012\right)$. Correcting the estimated $r$ for this inbreeding reduced the relatedness between nestmates to zero, implying that a very high number of unrelated queens are effectively breeding in the colonies $\left(n_{\mathrm{e}}=\infty\right.$ in the entire $\left.95 \% \mathrm{CI}\right)$. These results are in accordance with the population level analyses presented in Table 3. Furthermore, the lack of, or at most very modest, population- 
genetic structure within putative supercolonies demonstrates that the conditions for applying the BAPS algorithm to detect supercolonies as randomly mating subpopulation are fulfilled (Corander et al. 2003, 2004).

An inspection of nest location and supercolony assignment provides some information on the size and distribution of supercolonies (Fig. 2). The maximum distance between uninterrupted nest samples belonging to the same supercolony ranged from 25 to $500 \mathrm{~m}$ (an estimate of supercolony size is possible for those supercolonies where several nests were collected). On the other hand, some supercolonies were very close to each other, with the closest location of nests belonging to a different supercolony being separated by only $13 \mathrm{~m}$.

\section{DISCUSSION}

The relatedness between nestmate workers was significantly greater than zero in three of the four native populations, but not in any of the six introduced populations analyzed. Importantly, the occurrence of significant relatedness was invariably associated with a significant level of inbreeding, whereas no inbreeding was detected in the populations where relatedness was not significantly greater than zero. Correcting for the inflating effect of inbreeding resulted in estimates of relatedness being effectively equal to zero. Accordingly, in all native and introduced populations, the estimated number of queens contributing to reproduction was very high (Table 3 ).

Four lines of evidence support the view that the significant level of inbreeding found in three of the four native populations was caused by a subdivision into several genetically isolated supercolonies. First, the Bayesian analysis of microsatellite data provided a highly probable and geographically meaningful clustering of genetically similar nests. Second, this significant population structuring was well explained by the presence of several supercolonies per population with no significant genetic isolation by distance between them. Third, these subpopulations fitted the distribution of mitochondrial haplotypes with $73 \%$ of the overall variance occurring between supercolonies and only $13 \%$ within supercolonies. Finally, the behavioral observations were in accordance with the genetic data, with all observed aggressions occurring between workers from nests assigned to different supercolonies.

Our data show that gene flow is extremely limited between supercolonies. In Otamendi and Boca the differentiation at nuclear loci $\left(F_{\mathrm{ST}}=0.25\right)$ corresponds to less than one effective migrant per generation under equilibrium conditions. The differentiation at the mitochondrial gene studied was even higher $\left(\Phi_{\mathrm{ST}}=0.845\right)$, suggesting that female gene flow may be completely absent between supercolonies. These data are in accordance with the observation that, in introduced populations, queens do not disperse on the wing but mate within the parental nest (Markin 1970; Passera and Keller 1992). Moreover, a detailed population genetic study in a contact zone between the two European supercolonies also revealed an important genetic differentiation $\left(F_{\mathrm{ST}}=0.40\right)$ and complete lack of gene flow between supercolonies, even when nests were as close as $27 \mathrm{~m}$ (Jaquiéry et al. 2005).
In sum, our combined data unambiguously demonstrate that native populations of the Argentine ant are organized in supercolonies with large numbers of reproductive queens and very low relatedness among its members. Hence, native populations are not composed of many, family-based colonies as in the vast majority of other social insect species, but are unicolonial similar to introduced populations (Table 1). This fact has important implications for our understanding of the origin of unicoloniality. First, it disproves the current view of unicoloniality as a derived form of social organization that evolved after the introduction of Argentine ants into new environments (Tsutsui et al. 2000; Giraud et al. 2002; Tsutsui and Suarez 2003). It suggests that the various hypotheses that have been proposed to account for the evolution of unicoloniality were misconceived, because they are based on the incorrect assumption that a transition in the ant's social organization has occurred. Hence, there is currently no empirical support for the view that a loss of genetic diversity at recognition loci have played a key role in the evolution of unicoloniality (Tsutsui et al. 2000; Giraud et al. 2002; Tsutsui et al. 2003).

The second and related implication is that it is necessary to carefully study the composition and structure of native populations if one is to understand the evolution of unicoloniality. Our present study shows that the crucial difference between native and introduced populations is the size of supercolonies. In introduced populations, supercolonies can be huge, as exemplified by the European main supercolony ranging over several thousands of kilometers (Giraud et al. 2002). By contrast, the native supercolonies in Argentina are orders of magnitudes smaller, and typically had diameters of 25$500 \mathrm{~m}$ (Fig. 2). This is consistent with previous work indicating a range of native Argentinean supercolonies of 200$800 \mathrm{~m}$ (based on aggression tests; Tsutsui et al. 2000), about $600 \mathrm{~m}$ (based on pairwise estimates of $F_{\mathrm{ST}}$; Tsutsui and Case 2001 ), and from $10 \mathrm{~m}$ to $>1 \mathrm{~km}$ (based on aggression tests and mapping of nest networks; Heller 2004).

The relatively small size of native supercolonies makes it a less daunting task to explain the evolution and stability of unicoloniality. To some extent, those supercolonies can be considered as the end point of a continuum in social organization with strict monogyny at the other end and various levels of polygyny in between (Keller 1995). This begs the question of the most relevant scale to be considered when measuring relatedness and investigating the role of kin selection. Theoretical studies have shown that relatedness should be measured at the level of the "economic neighborhood,' that is, the scale at which intraspecific competition generally takes place (Taylor 1992; Kelly 1994; Queller 1994; Griffin and West 2002). Hence, if competition occurs mostly within supercolonies, relatedness should be measured at the scale of the supercolony with the effect that individuals collected in the same nest are effectively completely unrelated. By contrast, if supercolonies compete with each other, for example for access to territory, then the genetic differentiation between supercolonies should be considered when measuring relatedness. Hence, understanding to what extent reproductive altruism can be maintained by kin selection requires the determination of the relative level of competition within and between supercolonies. Although it is currently 
not possible to assess the relative importance of within- and between-supercolony competition, it is most likely that competition between supercolonies is higher when the size of supercolonies is smaller.

An important related issue is whether the level of altruism and cooperation may influence the life span of supercolonies and the likelihood that they would give rise to new supercolonies. If so, the early suggestion by Sturtevant (1938) that selection may take place at the colony level may be relevant for comprehending the evolutionary dynamics of these systems (Crozier 1979). In particular, this may allow supercolonies of unrelated individuals to be maintained over long evolutionary periods even if selfish traits, such as inducing larvae to develop into queens rather than workers (Crozier 1979; Bourke and Franks 1995; Queller and Strassmann 1998), occasionally evolve and lead to the extinction of the supercolony in which they spread. If supercolonies are regularly replaced by more competitive supercolonies, a subtle dynamical process between the spread of detrimental traits and the selective elimination of colonies with such traits may allow a stable equilibrium and the persistence of unicoloniality over considerable stretches of evolutionary time.

The detailed study of the six introduced populations revealed that in all of them the relatedness was indistinguishable from zero. Previous studies have already reported a lack of significant genetic differentiation between local nests in five populations in Europe, California, and Hawaii (Kaufmann et al. 1992; Krieger and Keller 2000; Tsutsui and Case 2001; Ingram 2002a; Ingram and Gordon 2003). However, it is the first time that a sufficient number of individuals, nests, and microsatellite loci were analyzed simultaneously to allow the conclusion that any meaningful structure at the nest level or population level would have been detected with a very high probability.

We did not investigate genetic population structure at a scale exceeding $5 \mathrm{~km}$ in the introduced range. However, structuring at a larger scale is unlikely to be an important force acting on social evolution in the Argentine ant because the economic neighborhood is very local in introduced populations. Thus, queens do not depart on mating flights but remain in their natal nest or disperse to neighborhood nests on foot (Passera and Keller 1992). Similarly, most males mate within their parental nest and the few males that disperse on the wing are unlikely to disperse farther than a few hundred meters (Markin 1970). Hence, the economic neighborhood clearly occurs at a scale of a few hundred meters. Since our study unambiguously revealed a lack of any genetic differentiation at this scale, kin selection is not a significant force maintaining the social structure in introduced populations.

In conclusion, this study revealed that both native and introduced populations of the Argentine ant are organized in supercolonies consisting of effectively unrelated individuals. Hence, the success of invasive ants such as L. humile does not stem from a shift in social organization associated with introduction into new habitats (Crozier 1979; Bourke and Franks 1995; Queller and Strassmann 1998; Queller 2000), but more likely from ecological conditions allowing such ants to dramatically extend the dimension of supercolonies in the introduced range. This increase in supercolony size decreases intraspecific competition and thus makes the Argentine ant an even more formidable competitor in introduced habitats. At the same time, by decreasing competition between supercolonies, increased supercolony size also provides greater opportunity for selfish mutants to spread and thus should lead to an instability of such systems over evolutionary time (Crozier 1979; Bourke and Franks 1995; Queller and Strassmann 1998; Queller 2000).

\section{ACKNOWLEDGMENTS}

We thank F. Cuezzo and I. Fernández-Escudero for invaluable help in the field; S. Bocherens, I. Dunand, P. Presi, C. Roger, and R. Vega for assistance in the laboratory; and J. Briano, L. Calcaterra, M. Chiotis, R. H. Crozier, P. D. Krushelnycky, and P. S. Ward for providing ant samples. A. E. Wild kindly confirmed the species identifications of Argentinean samples. J. J. Boomsma, M. Chapuisat, D. P. Hughes, and K. Parker gave valuable comments on a previous version of this manuscript. This study was supported by grants from the Swiss National Science Foundation, the Carlsberg Foundation, the Danish National Science Research Council, the Swiss Academy of Sciences, and the European Community's Improving Human Potential Programme under contract HPRN-CT-2000-00052 “INSECTS”.

\section{Literature Cited}

Benois, A. 1973. Incidence des facteurs écologiques sur le cycle annuel et l'activité saisonnière de la fourmi d'Argentine, Iridomyrmex humilis Mayr (Hymenoptera, Formicidae), dans la région d'Antibes. Insectes Soc. 20:267-295.

Bolger, D. T., A. V. Suarez, K. R. Crooks, S. A. Morrison, and T. J. Case. 2000. Arthropods in urban habitat fragments in southern California: area, age, and edge effects. Ecol. Appl. 10: 1230-1248.

Bourke, A. F. G., and N. R. Franks. 1995. Social evolution in ants. Princeton Univ. Press, Princeton, NJ.

Cole, F. R., A. C. Medeiros, L. L. Loope, and W. W. Zuehlke. 1992. Effects of the Argentine ant on arthropod fauna of Hawaiian high-elevation shrubland. Ecology 73:1312-1322.

Corander, J., P. Waldmann, and M. J. Sillanpää. 2003. Bayesian analysis of genetic differentiation between populations. Genetics 163:367-374.

Corander, J., P. Waldmann, P. Marttinen, and M. J. Sillanpää. 2004 BAPS 2: enhanced possibilities for the analysis of genetic population structure. Bioinformatics 20:2363-2369.

Crozier, R. H. 1979. Genetics of sociality. Pp. 223-286 in H. R. Hermann, ed. Social insects. Academic Press, New York.

Crozier, R. H., and P. Pamilo. 1996. Evolution of social insect colonies: sex allocation and kin selection. Oxford Univ. Press, Oxford, U.K.

Excoffier, L., P. E. Smouse, and J. M. Quattro. 1992. Analysis of molecular variance inferred from metric distances among DNA haplotypes: application to human mitochondrial DNA restriction data. Genetics 131:479-491.

Fournier, D., and L. Keller. 2001. Partitioning of reproduction among queens in the Argentine ant, Linepithema humile. Anim. Behav. 64:697-708.

Giraud, T., J. S. Pedersen, and L. Keller. 2002. Evolution of supercolonies: the Argentine ants of southern Europe. Proc. Natl. Acad. Sci. USA 99:6075-6079.

Goudet, J. 1995. FSTAT (version 1.2): a computer program to calculate $F$-statistics. J. Hered. 86:485-486.

Goudet, J., M. Raymond, T. De Meeüs, and F. Rousset. 1996. Testing differentiation in diploid populations. Genetics 144: $1933-1940$

Griffin, A. S., and S. A. West. 2002. Kin selection: fact and fiction. Trends Ecol. Evol. 17:15-21. 
Hamilton, W. D. 1964. The genetical evolution of social behaviour I-II. J. Theor. Biol. 7:1-52.

Heller, N. E. 2004. Colony structure in introduced and native populations of the invasive Argentine ant, Linepithema humile. Insectes Soc. 51:378-386.

Hölldobler, B., and E. O. Wilson. 1977. The number of queens: an important trait in ant evolution. Naturwissenschaften 64:8-15.

_ 1990. The ants. Springer-Verlag, New York.

Holway, D. A., and A. V. Suarez. 2004. Colony-structure variation and interspecific competitive ability in the invasive Argentine ant. Oecologia 138:216-222.

Holway, D. A., A. V. Suarez, and T. D. Case. 1998. Loss of intraspecific aggression in the success of a widespread invasive social insect. Science 282:949-952.

Human, K. G., and D. M. Gordon. 1996. Exploitation and interference competition between the invasive Argentine ant, Linepithema humile, and native ant species. Oecologia 105:405-412.

Ingram, K. K. 2002a. Plasticity in queen number and social structure in the invasive Argentine ant (Linepithema humile). Evolution 56:2008-2016.

- 2002b. Flexibility in nest density and social structure in invasive populations of the Argentine ant, Linepithema humile. Oecologia 133:492-500.

Ingram, K. K., and D. M. Gordon. 2003. Genetic analysis of dispersal dynamics in an invading population of Argentine ants. Ecology 84:2832-2842.

Jaquiéry, J., V. Vogel, and L. Keller. 2005. Multilevel genetic analyses of two European supercolonies of the Argentine ant, $\mathrm{Li}$ nepithema humile. Mol. Ecol. 14:589-598.

Kaufmann, B., J. J. Boomsma, L. Passera, and K. N. Petersen. 1992. Relatedness and inbreeding in a French population of the unicolonial ant Iridomyrmex humilis (Mayr). Insectes Soc. 39: 195-200.

Keller, L. 1995. Social life: the paradox of multiple-queen colonies. Trends Ecol. Evol. 10:355-360.

Keller, L., and D. Fournier. 2002. Lack of inbreeding avoidance in the Argentine ant Linepithema humile. Behav. Ecol. 13:28-31.

Keller, L., and L. Passera. 1992. Mating system, optimal number of matings, and sperm transfer in the Argentine ant Iridomyrmex humilis. Behav. Ecol. Sociobiol. 31:359-366.

- 1993. Incest avoidance, fluctuating asymmetry, and the consequences of inbreeding in Iridomyrmex humilis, an ant with multiple queen colonies. Behav. Ecol. Sociobiol. 33:191-199.

Kelly, J. K. 1994. The effect of scale dependent processes on kin selection: mating and density regulation. Theor. Popul. Biol. 46: 32-57.

Krieger, M. J. B., and L. Keller. 1999. Low polymorphism at 19 microsatellite loci in a French population of Argentine ants ( $\mathrm{Li}$ nepithema humile). Mol. Ecol. 8:1078-1080.

- 2000. Mating frequency and genetic structure of the Argentine ant Linepithema humile. Mol. Ecol. 9:119-126.

Maddison, W. P., and D. R. Maddison. 1992. MacClade: analysis of phylogeny and character evolution. Sinauer, Sunderland, MA.

Markin, G. P. 1970. The seasonal life cycle of the Argentine ant, Iridomyrmex humilis (Hymenoptera: Formicidae), in southern California. Ann. Entomol. Soc. Am. 63:1238-1242.

Newell, W., and T. C. Barber. 1913. The Argentine ant. US Dep. Agric. Bur. Entomol. Bull. 122:1-98.

Pamilo, P. 1983. Genetic differentiation within subdivided populations of Formica ants. Evolution 37:1010-1022.

_ 1985 . Effect of inbreeding on genetic relatedness. Hereditas 103:195-200.

Passera, L. 1994. Characteristics of tramp species. Pp. 23-43 in D. F. Williams, ed. Exotic ants: biology, impact, and control of introduced species. Westview Press, Boulder, CO.

Passera, L., and L. Keller. 1990. Loss of mating flight and shift in the pattern of carbohydrate storage in sexuals of ants (Hymenoptera, Formicidae). J. Comp. Physiol. B 160:207-211.

.1992. The period of sexual maturation and the age at mating in Iridomyrmex humilis, an ant with intranidal mating. J. Zool. Lond. 228:141-153.

1994. Mate availability and male dispersal in the Argentine ant Linepithema humile. Anim. Behav. 48:361-369.

Pedersen, J. S., and J. J. Boomsma. 1999. Effect of habitat saturation on the number and turnover of queens in the polygynous ant, Myrmica sulcinodis. J. Evol. Biol. 12:903-917.

Queller, D. C. 1994. Genetic relatedness in viscous populations. Evol. Ecol. 8:70-73.

$$
\text { 2000. Pax Argentinica. Nature 405:519-520. }
$$

Queller, D. C., and K. F. Goodnight. 1989. Estimating relatedness using genetic markers. Evolution 43:258-275.

Queller, D. C., and J. E. Strassmann. 1998. Kin selection and social insects. BioScience 48:165-175.

Reuter, M., J. S. Pedersen, and L. Keller. 2005. Loss of Wolbachia infection during colonisation in the invasive Argentine ant $\mathrm{Li}$ nepithema humile. Heredity 94:364-369.

Rice, W. R. 1989. Analyzing tables of statistical tests. Evolution 43:223-225.

Rissing, S. W., and G. B. Pollock. 1988. Pleometrosis and polygyny in ants. Pp. 179-222 in R. L. Jeanne, ed. Interindividual behavioral variability in social insects. Westview Press, Boulder, CO.

Ross, K. G. 2001. Molecular ecology of social behaviour: analyses of breeding systems and genetic structure. Mol. Ecol. 10: $265-284$.

Sanders, N. J., N. J. Gotelli, N. E. Heller, and D. M. Gordon. 2003. Community disassembly by an invasive species. Proc. Natl. Acad. Sci. USA 100:2474-2477.

Schneider, S., D. Roessli, and L. Excoffier. 2001. Arlequin: a software for population genetics data analysis. Genetics and $\mathrm{Bi}$ ometry Laboratory, University of Geneva, Geneva.

Starks, P. T. 2003. Selection for uniformity: xenophobia and invasion success. Trends Ecol. Evol. 18:159-162.

Sturtevant, A. H. 1938. Essays on evolution. II. On the effects of selection on social insects. Q. Rev. Biol. 13:74-76.

Suarez, A. V., N. D. Tsutsui, D. A. Holway, and T. J. Case. 1999. Behavioral and genetic differentiation between native and introduced populations of the Argentine ant. Biol. Invasions 1: 43-53.

Suarez, A. V., D. A. Holway, D. Liang, N. D. Tsutsui, and T. D. Case. 2002. Spatio-temporal patterns of intraspecific aggression in the invasive Argentine ant. Anim. Behav. 64:697-708.

Taylor, P. D. 1992. Altruism in viscous populations: an inclusive fitness model. Evol. Ecol. 6:352-356.

Tsutsui, N. D., and T. J. Case. 2001. Population genetics and colony structure of the Argentine ant (Linepithema humile) in its native and introduced ranges. Evolution 55:976-985.

Tsutsui, N. D., and A. V. Suarez. 2003. The colony structure and population biology of invasive ants. Conserv. Biol. 17:48-58.

Tsutsui, N. D., A. V. Suarez, D. A. Holway, and T. J. Case. 2000. Reduced genetic variation and the success of an invasive species. Proc. Natl. Acad. Sci. USA 97:5948-5953.

Tsutsui, N. D., A. V. Suarez, and R. K. Grosberg. 2003. Genetic diversity, asymmetrical aggression, and recognition in a widespread invasive species. Proc. Natl. Acad. Sci. USA 100: 1078-1083.

Visser, D., M. G. Wright, and J. H. Giliomee. 1996. The effect of the Argentine ant, Linepithema humile (Mayr) (Hymenoptera: Formicidae), on flower-visiting insects of Protea nitida Mill. (Proteaceae). Afr. Entomol. 4:285-287.

Wild, A. L. 2004. Taxonomy and distribution of the Argentine ant, Linepithema humile (Hymenoptera: Formicidae). Ann. Entomol. Soc. Am. 97:1204-1215.

Corresponding Editor: U. Mueller 